\title{
Effect of topical vasodilator on internal thoracic artery blood flow. A placebo-controlled clinical study
}

\author{
Cenap Ozkara ${ }^{1}$, Omer Faruk Dogan ${ }^{2}$, Cevdet Furat ${ }^{3}$ \\ ${ }^{1}$ Department of Cardiovascular Surgery, Corlu Sifa Hospital, Istanbul, Turkey \\ ${ }^{2}$ Department of Cardiovascular Surgery, Adana Numune Education and Training Hospital, Adana, Turkey \\ ${ }^{3}$ Zonguldak Ereğli Devlet Hastanesi, Zonguldak, Turkey \\ Email: ofdogan@hacettepe.edu.tr
}

Received 29 March 2012; revised 25 April 2012; accepted 7 May 2012

\section{ABSTRACT}

Objective: The internal thoracic artery (ITA) is the conduit of choice for coronary artery bypass grafting (CABG). To avoid spasm of the ITA various topical vasodilators have been suggested either intraluminally or by topical application. In order to describe the best vasodilating agent for preparation of the ITA, a randomized double-blind placebo controlled clinical work was performed in a group of CABG patients. Methods: Three hundred consecutive patients submitted for elective first time coronary artery bypass grafting were randomly subdivided into five groups. The first measurement was performed shortly after the internal thoracic artery was dissected from the chest wall and the second just prior to performing distal anastomosis to the left anterior descending coronary artery. During the time interval between the two measurements topical vasodilator has been injected into the endothoracic fascia of the ITA using the following drugs: papaverine $2 \mathrm{mg} / \mathrm{ml}$, nitroglycerin $1 \mathrm{mg} / \mathrm{ml}$, nitroprusside $0.5 \mathrm{mg} / \mathrm{ml}$, mixed solution include sodium nitroprusside $(1 \mathrm{mg} / \mathrm{ml})$ and diltiazem $(0.5 \mathrm{mg} / \mathrm{ml})$ and normal saline $0.9 \%$. Results: No statistically significant differences were found between the groups in respect to age, body surface area, cardiopulmonary bypass time, cross clamping time, and time interval between the two flow measurements. Mean arterial pressure at the time of the first and second internal thoracic artery flow measurements did not show statistically significant differences either within or between the groups. In all five groups, the free flow of the internal thoracic artery increased significantly with time. However, no statistically significant differences were shown between the five groups with respect to second flow. Conclusions: We suggest that preparation of the ITA by topical vasodilators injection into the endothoracic fascia does not result in a significantly superior free flow than placebo.
Keywords: Coronary Artery Disease; Vasospasm; Topical Vasodilators

\section{INTRODUCTION}

The internal thoracic artery is the conduit of choice for coronary artery bypass grafting. The use of an ITA to the left anterior descending (LAD) artery is associated with a superior patency rate when compared with vein grafts. However, perioperative ITA spasm with insufficient early graft flow has been reported. For inhibition of the conduit spasm many surgeons are used different topical vasodilators in CABG operations. Previous clinical studies have showed that many of surgeons have suggested the use of vasodilators into the ITAs' pedicle or into the lumen for an attempt to minimize ITA spasm. On the other side, some of the authors have showed that vasodilator application has not provide vasodilator effect. Thus, there is no common concensus about the routine use of topical vasodilator agents. This study was designed to determine the effectiveness of commonly used vasodilator drugs in inhibiting vasospasm and increasing flow of the ITA prior to ITA-LAD artery anastomosis.

\section{PATIENTS AND METHODS}

The study comprised 300 patients underwent harvesting of the ITA in preparation for CABG. Patients who were in hemodynamically unstable condition or showed evidence of ischemia during the operation excluded from this study. Chronic renal failure patients were also excluded from this work. Patients divided into five groups. In group1 $(\mathrm{n}=54)$, vasodilator response to nitroprusside solution ( $1 \mathrm{mgr}$ diluted with $20 \mathrm{~mL}$ saline) was investigated. In group $2,(\mathrm{n}=74)$, glyceril trinitrate $(5 \mathrm{mg} / 10$ $\mathrm{mL}$ normal saline) was applied. In group 3, $(\mathrm{n}=72)$, papaverine (5 $\mathrm{ml}$ in $20 \mathrm{~mL}$ of normal saline) was used. In group 4 (42 patients) we used mixed vasodilator agent included sodium nitroprusside and diltiazem ( $3 \mathrm{mgr}$ diluted with $20 \mathrm{~mL}$ saline solution, $1 \mathrm{mgr}$ sodium nitro- 
prusside and 2 mgr diltiazem). In group $5(\mathrm{n}=58)$, as a control group, saline solution was used.

The ITA with the pedicle was mobilized from the subclavian vein to below the bifurcation of the ITA with the use of low voltage electrocauttery. Heparin, 300 units $/ \mathrm{kg}$, was administered intravenously before transection of the ITA. The artery was then cutted at least $1-2 \mathrm{~cm}$ proximal to the bifurcation. The first measurement was recorded immediately after harvesting before treatment and CPB (Flow 1). For flow measurement, the ITA bled freely into the cab for a minute. After the clipping of the artery, topical vasodilator was injected into the pedicle over its entire length with thin needle and The ITA pedicle was wrapped in a soaked gauze pad and waited until anastomosis. All ITA length was noted before the flow measurements.

Flow 1 of the groups was as follows:

In group 1: $68.1 \pm 20.7 \mathrm{ml} / \mathrm{min}$;

In group 2: $55.8 \pm 14.8 \mathrm{ml} / \mathrm{min}$;

In group 3: $49.8 \pm 11.6 \mathrm{ml} / \mathrm{min}$;

In group 4: $48.0 \pm 13 \mathrm{ml} / \mathrm{min}$;

In group 5: $44.63 \pm 3 \mathrm{ml} / \mathrm{min}$.

The vasodilatory substances applied to the ITA were as follows: group I $(\mathrm{n}=54), 20 \mathrm{~mL}$ of sodium nitroprusside (1mgr diluted with $20 \mathrm{cc}$ saline), group $2(\mathrm{n}=74),(5 \mathrm{mg}$ nitroglycerine in $10 \mathrm{~mL}$ normal saline). In group $3(\mathrm{n}=$ 72), $10 \mathrm{~mL}$ of papaverine, $5 \mathrm{mg} / 10 \mathrm{~mL}$ saline; group 4 (n $=58$ ), and $20 \mathrm{~mL}$ of saline solution was injected into the pedicle in the periarterial tissue along the length of the pedicle.

The same surgeons, DoganOF and Ozkara C, MD., performed all operations. Drugs were prepared in sealed bottles and coded in the hospital pharmacy. Thus, surgeon and asistant were blinded to the drug type.

The second flow (Flow 2) was determined just before the anastomosis the ITA to the LAD artery in the same way. The ITA length, heart rate, mean blood pressure were recorded for each flow measurement. The time between flows 1 and 2 was recorded.

Flow 2 of the groups was as follows:

In group 1: $96.3 \pm 17 \mathrm{ml} / \mathrm{min}$;

In group 2: $84.3 \pm 13 \mathrm{ml} / \mathrm{min}$;

In group 3: $78.8 \pm 13.6 \mathrm{ml} / \mathrm{min}$;

In group 4: $73 \pm 9.4 \mathrm{ml} / \mathrm{min}$;

In group 5: $98.50 \pm 12 \mathrm{ml} / \mathrm{min}$.

\section{STATISTICAL ANALYSIS}

Results are showed as mean \pm standard error. In order to analyze statistically significant differences in mean continuous parameters (age, number of diseased coronary arteries, time between the flow measurements, etc.) between the four groups analysis of variance was done using the Duncan multiple comparison test. A non-parametric analysis of Kruska-Wallis Test was also used.
Paired t-test was used in order to analyze statistically significant differences between first and second flow measurements specific for each groups. P values less or equal to 0.05 were considered statistically significant.

\section{RESULTS}

The demographic and hemodynamic data of five groups are shown in Table 1. There were no significant changes between the groups with respect to sex ratio, ITA length, aortic cross clamp time and time between the first and second flow measurement in all groups. Group 1 through 5 displayed no significant differences in heart rate (pre$\mathrm{CPB}$ ) and mean blood pressure measurements from flow 1 to flow 2 within each group. Flow measurements of the five groups are shown in Table 2. For each group, there was no significant increase in flow from flow 1 to flow 2 $(\mathrm{P}>0.05)$ (Table 2). When corrected for age, mean arterial pressure, and length of the ITA, time between measurements no significant differences were found between the groups $(\mathrm{P}>0.05)$.

In all groups the free flow of the ITA immediately prior to ITA-LAD anastomosis was significantly higher compared to the post division free flow $(\mathrm{P}<0.003$, $0.0002,0.0003,0.02,0.0003$, respectively) (Table 2). However, no statistically significant differences were shown between the five groups.

No patient was excluded from the study due to the Fsame reasons such as ITA dissection. In nitroprusside group, moderate hypotension developed after the vasodilator application in 8 patients but in a few minutes it has been corrected with the volume loading. No mortality was seen after operation. Postoperative cardiac cardiac enzyme analyses and electrocardiogarphy was recorded from all patients. There was no evidence of myocardial ischemia after operation.

\section{DISCUSSION}

The ITA is the conduit of choice for myocardial revascularization because of its proven long-term patency rate [1-3]. However, conduit spasm during harvesting of the ITA with early graft failure has been reported and can cause perioperative myocardial ischemia $[4,5]$. In order to suitable blood flow, various topical or intraluminal vasodilators, as well as mechanical dilatation of the artery, have been used to prevent or reverse vasospasm [6,7]. Most of the studies examining the effect of topical vasodilators were done in vitro or following different mechanical manipulations [8,9]. However, there is no common concensus in order to provide antivasospasm approach. This study was designed to determine the effectiveness of commonly used vasodilator drugs by the surgeons in inhibiting vasospasm and increasing blood flow of the ITA prior to ITA-left descending artery (LAD) 
Table 1. The demographic and hemodynamic data of five groups and $\mathrm{P}$ values.

\begin{tabular}{|c|c|c|c|c|c|c|}
\hline Patients Charecteristics & Group I & Group II & Group III & Group IV & Group V & P Value \\
\hline Mean age (years) & $62 \pm 2.1$ & $59 \pm 1.1$ & $66 \pm 4.4$ & $61 \pm 4.4$ & $65 \pm 3.2$ & $\mathrm{P}=1.0$ \\
\hline Gender (M/F) & Oct-44 & $56 / 18$ & $57 / 15$ & $27 / 15$ & $39 / 19$ & \\
\hline No. of graft & $3.4 \pm 1.2$ & $4.1 \pm 1.1$ & $3.3 \pm 1.1$ & $3.4 \pm 1.1$ & $3.1 \pm 1.3$ & $\mathrm{P}=0.4$ \\
\hline Mean CPB time (min.) & $59.6 \pm 3.2$ & $54.3 \pm 5.2$ & $53.4 \pm 4.1$ & $58.2 \pm 5.1$ & $55.4 \pm 2.4$ & $\mathrm{P}=1.0$ \\
\hline Mean AoXClamp time (min.) & $47 \pm 5$ & $42 \pm 8$ & $51 \pm 9$ & $49 \pm 9$ & $3 \pm 6$ & $\mathrm{P}=0.7$ \\
\hline $\begin{array}{l}\text { Mean blood pressure }(\mathrm{mm} / \mathrm{Hg}) \\
\text { (pre-CPB) }\end{array}$ & $74.1 \pm 3.4$ & $68.6 \pm 1.3$ & $64.6 \pm 2.4$ & $67.8 \pm 2.5$ & $62.7 \pm 3.2$ & $\mathrm{P}=0.3$ \\
\hline $\begin{array}{l}\text { Mean blood pressure }(\mathrm{mm} / \mathrm{Hg}) \\
\text { (during Ao cross clamp) }\end{array}$ & $44 \pm 9$ & $57 \pm 7$ & $45 \pm 4$ & $44 \pm 4$ & $51 \pm 3$ & $\mathrm{P}=0.4$ \\
\hline ITA length $(\mathrm{cm})$ & $14 \pm 3$ & $16 \pm 2$ & $15 \pm 1$ & $13 \pm 8$ & $13 \pm 2$ & $\mathrm{P}=0.8$ \\
\hline
\end{tabular}

Table 2. ITA flow rates before and after treatment.

\begin{tabular}{ccccccc}
\hline & Group I & Group II & Group III & Group IV & Group V & P Value \\
\hline First flow (ml/min.) & $68.1 \pm 20.7$ & $55.8 \pm 14.8$ & $49.8 \pm 11.6$ & $48.0 \pm 13$ & $44.63 \pm 3$ & 0.5 \\
Second flow (ml/min.) & $96.3 \pm 17$ & $84.3 \pm 13$ & $78.8 \pm 13.6$ & $73 \pm 9.4$ & $98.50 \pm 12$ & 0.4 \\
P-value & 0.003 & 0.002 & 0.003 & 0.02 & 0.003 & \\
\hline
\end{tabular}

anastomosis. According to the previous study [10] that ITA flow is low immediately after its mobilization from the chest wall in number of CABG patients. This result is confirmed that vasospasm may be triggered by mechanical manipulation and physical factors such as diathermy or hypotension $[11,12]$.

Some of the authors have reported similar results after vasodilator agent usage. Sasson et colleagues and Nilia et al. have shown that topical vasodilators had no effect on ITA flow and the only factor influencing the flow was time $[9,10]$. There are a few major differences in the methods used by our group compared to previously published reports. Firstly, unlike other previous reports, our study was randomized and placebo-controlled. Secondly, our groups include the largest patient study group than previously reported patients. On the other side, in previous studies, the effect of topical or intraluminal use of vasodilators was examined by measuring the ITA free flow before initiation of CPB, thus the time interval between the pre and post-treatment was usually shorter than 20 min. Instead, we performed the second ITA flow measurement just prior to constructing the ITA-LAD anastomosis on CPB. This allowed an average time interval of 35 - $45 \mathrm{~min}$. between the two flow measurements. In this study, all groups including the control saline group, achieved satisfactory flows in the range of 50 $\pm 9 \mathrm{mil}$./min. and there was no clinical evidence of hypoperfusion during the immediate perioperative period. In many of study, the authors have exhibited the statistically significant increase in ITA flow using different vasodilator drugs such as nitroglycerine, papaverine, calcium receptor blocking agent, etc. However, in some study, the authors have showed that sodium nitroprusside has only been accepted as an effective vasodilator agent [12].

When we examined English literature, in Jett et al., experimental inhibition of the contraction of precontracted ITA rings was best achieved with calcium channel blocker, sodium nitroprusside and papaverine, with the least or no effect achieved with nitroglycerin [8]. He et colleagues found that glyceryl trinitrate was more potent than papaverine in relaxing precontracted ITA rings, while nifedipine took a longer time to achieve this relaxation [13].

We have not found the statistical difference between the effect of sodium nitroprusside, papaverine, glyceryl trinitrate, mixed solution and normal saline. Our results may be explained by the fact that this time the artery underwent spontaneous dilatation.

It is widely accepted that the endothelium of the ITA spontaneously releases significant amounts of nitric oxide which plays an important role in arterial vasodilatation. In addition, production of nitric oxide may be stimulated by a variety of vasoactive substances. It has been suggested that blood vessels with intact endothelium reacts poorly to vasoconstrictors whereas they contract strongly when endothelium is lost or damaged [14].

In our opinion for explanation of this effect; ITA blood flow is decreased after the first mechanical or thermal maniplation, and if the endothelium is intact, not dissected, a time related recovery takes place during the operation. This is probably due to the release of endothelial relaxing factors from the ITA endothelial cells. In our study has also two important points. One of this; the artery is transected at least $1-2 \mathrm{~cm}$ proximal to the ITA bifurcation in all patients. This allows resection of the 
muscular segment of the ITA and a minimization of spasm. The second important point; the longer period between the two measurements in our study allowed the ITA spasm to lost spontaneously, thus negating the effect of the topical vasodilators.

In conclusion, this study has shown that careful harvesting (no touch technique) in a wide pedicle and trimmed more than $2 \mathrm{~cm}$ proximal to the bifurcation is seems to be a gold standart for the ITA conduit blood flow. In this condition the ITA is not needed for further pharmacological treatment. If blood flow is weakly, keep should in mind we can wait before the artery has made a fully spontaneous recovery from the spasm. Vasodilator treatment with the use of sodium nitroprusside may be help to provide suitable blood flow from the ITA. But we should remembre that systemic hypotension after nitroprusside application is a main side effect in some patients.

\section{REFERENCES}

[1] Loop, F.D., Lytle, B.W., Cosgrove, D.M., Stewart, R.W., Goormastic, M., Williams, G.W., Golding, L.A., Gill, C.C., Taylor, P.C. and Sheldon, W.C. (1986) Influence of the internal mammary graft on 10 year survival and other cardiac events. The New England Journal of Medicine, 314, 1-6. doi:10.1056/NEJM198601023140101

[2] Lytle, B.W., Loop, F.D., Cosgrove, D.M., Ratliff, N.B., Easley, K. and Taylor, P.C. (1985) Long-term (5-12 years) serial studies of internal mammary artery and saphenous vein coronary bypass grafts. Journal of Thoracic and Cardiovascular Surgery, 89, 248-258.

[3] Yekeler, I., Pac, M., Kocak, H., Ates, A., Basoglu, A., Ege, E., Reis, A.K. and Aydın, M.E. (1993) Atherosclerosis in the internal mammary artery and comparison of the risk factors. Turkiye Klinikleri Journal of Medical Sciences, 11, 89-92.

[4] Barner, H.B. (1973) Blood flow in the internal mammary artery. American Heart Journal, 86, 570-571. doi:10.1016/0002-8703(73)90151-8
[5] Sarabu, M.R., McClung, J.A., Fass, A. and Red, G.E. (1987) Early postoperative spasm in the left internal mammary bypass artery. Annals of Thoracic Surgery, 44, 195-200. doi:10.1016/S0003-4975(10)62041-3

[6] Green, G.E. (1979) Techniques of internal mammarycoronary artery anastomosis. Journal of Thoracic and Cardiovascular Surgery, 78, 455-459.

[7] Mills, N.M. and Bringaze, W.L. (1989) Preparation of the internal mammary artery graft: Which is the best method? Journal of Thoracic and Cardiovascular Surgery, 98, 7379.

[8] Jett, G.K., Guyton, R.A., Hetcher, C.R. and Abel, P.W. (1992) Inhibition of human internal mammary artery contractions. Journal of Thoracic and Cardiovascular Surgery, 104, 977-982.

[9] Sasson, L., Cohen, A.J., Hauptman, E. and Schachner, A. (1994) Effect of topical vasodilators on internal mammary arteries. Annals of Thoracic Surgery, 59, 494-496. doi:10.1016/0003-4975(94)00896-F

[10] Nilia, M., Stamlera, A., Sulkesa, J. and Vidne, B.A. (1999) Preparation of the internal thoracic artery by vasodilator drugs: Is it really necessary? A randomized double-blind placebo-controlled clinical study. European Journal Cardio-Thoracic Surgery, 16, 560-563. doi:10.1016/S1010-7940(99)00308-5

[11] Canzer, C.C. and Dame, N.A. (1994) Ultrasonic assessment of internal thoracic artery graft flow in the revascularized heart. Annals of Thoracic Surgery, 58, 135-138. doi:10.1016/0003-4975(94)91087-1

[12] Cooper, G.J., Wilkinson, G.A.L. and Angelini, G.A. (1992) Overcoming perioperative spasm of the internal mammary artery. Which is the best vasodilator? Journal of Thoracic and Cardiovascular Surgery, 104, 465-468.

[13] He, G.W., Rosenfeldt, F.L., Buxton, B.F. and Angus, J.A. (1989) Reactivity of human isolated internal mammary artery to constrictor and dilator agent. Circulation, $\mathbf{8 0}$, 141-150.

[14] Yang, Z. and Lyscher, T.F. (1996) Biological and vasomotor properties of the internal thoracic artery: Role of the endothelium. In: Angelini, G.D, Brian, A.J. and Dion, R., Eds., Arterial Conduits in Myocardial Revascularization, Arnold, 23-31.

CPB: Cardiopulmonary bypass

AoX Clamp: Aortic cross clamp

P-values: Were calculated from Kruskal-Wallis test 